\title{
Characterization of Rhizoctonia solani Associated with Black Scurf in Cyprus
}

Loukas Kanetis, Dimitris Tsimouris, and Michalakis Christoforou, Department of Agricultural Sciences, Biotechnology and Food Science, Cyprus University of Technology, CY-3603, Limassol, Cyprus

\begin{abstract}
Kanetis, L., Tsimouris, D., and Christoforou, M. 2016. Characterization of Rhizoctonia solani associated with black scurf in Cyprus. Plant Dis. 100:1591-1598.

During 2011, 96 sclerotial isolates of Rhizoctonia solani were collected from potato tubers from all main potato-cultivating regions of Cyprus. All isolates were found to be multinucleate. Characterization of anastomosis groups (AG) based on hyphal anastomosis reactions showed that 91 isolates belonged to AG3 and 5 to AG4. Sequence analysis of the internal transcribed spacer (ITS) regions (ITS1 and ITS2) of ribosomal DNA (rDNA) of 68 isolates confirmed the prevalence of AG3. In addition, phylogenetic analysis found that AG3 isolates were of the potato type, distinctly separated from the AG3 tobacco type, while AG4 isolates were separated into two different subgroups (HGI and HGII). Temperature studies showed that isolates belonging to both AG4 subgroups had significantly higher optimum growth temperatures compared with AG3. In vitro sensitivities to the fungicide pencycuron, in terms of concentrations where $50 \%$ growth inhibition was observed, ranged from

0.012 to $0.222 \mu \mathrm{g} / \mathrm{ml}$. Pathogenicity and aggressiveness of the isolates was determined on 'Annabelle' potato sprouts and seedlings of a number of selected hosts, based on crop rotations followed in Cyprus. The majority of the isolates were pathogenic to potato sprouts, with disease severity (DS) values ranging from 0 to $88 \%$. Mean DS values were statistically different among AG and subgroups, with AG4-HGI (69.25\%) and AG4-HGII $(3.12 \%)$ being the most and least aggressive, respectively. However, AG4-HGII isolates were the most aggressive in all rotational hosts tested, while AG3 isolates were the least aggressive. More specifically, the highest DS levels by AG4-HGI were recorded to barley, by AG4-HGII to lettuce and melon, and by AG3 isolates to vetch. This is the first comprehensive study to elucidate the AG composition, pathogenicity and other biological aspects of $R$. solani isolates associated with potato black scurf in Cyprus.
\end{abstract}

Potato (Solanum tuberosum L.) production is one of the most dynamic sectors of Cyprus agriculture, significantly contributing to the economy of the country. Almost $50 \%$ of Cyprus agricultural export revenue, valued at an estimated $€ 30$ million, is attributed to potato, with $>60 \%$ of the annual production being exported, primarily to other European countries (Cyprus Statistical Service 2015). Crop production in Cyprus is divided into two seasons (spring and fall) covering approximately 4,550 ha (data of 2011 to 2012; Cyprus Statistical Service 2015). The local potato industry is characterized by limited and highly fragmented crop land and narrow application of crop rotation schemes, while the majority of the seed potato is imported from northern European countries. Furthermore, Cyprus crop production is constrained by marginal environmental conditions, with limited precipitation and high temperatures. Although the potato production system is highly resource intensive in fertility inputs, yield losses pose a continuous challenge for the industry.

The basidiomycete Rhizoctonia solani Kühn (teleomorph Thanatephorus cucumeris (A. B. Frank) Donk) is considered the most ubiquitous species within a heterogeneous genus of soilborne fungi, characterized by a global distribution and pathogenic on a wide variety of major crops (Bacharis et al. 2010; Cubeta and Vilgalys 1997). Population genetics and biology research designates $R$. solani as a species complex, because it accumulates related but genetically distinct groups with diverse morphology, ecology, and pathology (Cubeta and Vilgalys 1997; Hane et al. 2014). Thus, $R$. solani has been classified into 13 reproductively incompatible groups based on the anastomosis group (AG) concept, numbered from AG1 to AG13 (Carling et al. 2002). The complexity of the species has led to the further subdivision of many AG into subgroups that differ for one or more biochemical, genetic, or pathogenic characteristics (Cubeta and Vilgalys 1997).

$R$. solani is the causal agent of the Rhizoctonia potato disease that comprises two main pathosystems, stem canker and black scurf. Each

Corresponding author: L. Kanetis; E-mail: loukas.kanetis@cut.ac.cy

Accepted for publication 25 February 2016.

http://dx.doi.org/10.1094/PDIS-10-15-1238-RE

(C) 2016 The American Phytopathological Society pathosystem is clearly separated in terms of symptomatology, affected plant parts, and temporal distribution within the crop season. Stem canker results in quantitative losses by sprout, stolon, and root infections, mainly early in the season, affecting tuber size and number, whereas black scurf develops during plant senescence and is associated with the formation of sclerotia on progeny tubers and their malformation (Das et al. 2014; El Bakali and Martin 2006; Tsror 2010). Rhizoctonia potato disease accounts for significant marketable yield losses of up to $30 \%$ (Carling et al. 1989). In addition to the aforementioned typical symptoms, $R$. solani has been associated with other types of blemishes on potato tubers that include cracking, malformation, pitting, desquamation, and elephant hide (Campion et al. 2003; Fiers et al. 2011; Muzhinji et al. 2014; Tsror 2010). Furthermore, chlorosis and purpling of potato leaves, white collar at the stem base, and formation of aerial tubers are some of the reported aboveground symptoms of Rhizoctonia spp. (Tsror 2010) while, recently, Woodhall et al. (2008) reported severe damage of potato root system by AG8.

Host specificity among AG is variable (Carling et al. 2002; Fiers et al. 2011). Originally it was thought that AG3 infects only potato; however, isolates of this group have been reported to also infect eggplant, maize, tobacco, tomato, and sugar beet (Das et al. 2014; El Bakali and Martin 2006; McCormack et al. 2013; Miles et al. 2013). Thus, AG3 has been divided into three genetically distinct subgroups: AG3-PT (potato type), AG3-TM (tomato type), and AG3-TB (tobacco type), based on sequence variation in ribosomal DNA (rDNA) and $\beta$-tubulin genes, culture appearance, fatty acid profile, and pathogenicity (Bartz et al. 2010; Gonzalez et al. 2001; González et al. 2006; Misawa and Kuninaga 2010).

Different AG have been associated with potato; however, AG3-PT in particular is recognized as the more significant and predominant causal agent of both stem canker and black scurf, as well as other blemishes (Fiers et al. 2011; Lehtonen et al. 2008; Muzhinji et al. 2015; Woodhall et al. 2007). However, in lower frequencies, AG2-1 (Carling et al. 1989; Lehtonen et al. 2008; Woodhall et al. 2007), AG2-2 (Yanar et al. 2005), AG2-2IIIB (Muzhinji et al. 2015), AG4 (Carling et al. 1989; Tsror 2010), and AG5 (Lehtonen et al. 2008; Woodhall et al. 2007) are also associated with the crop, demonstrating variable pathogenicity and disease types. Subgroup AG2-1 is mainly associated with stem canker, with variable genetic and 


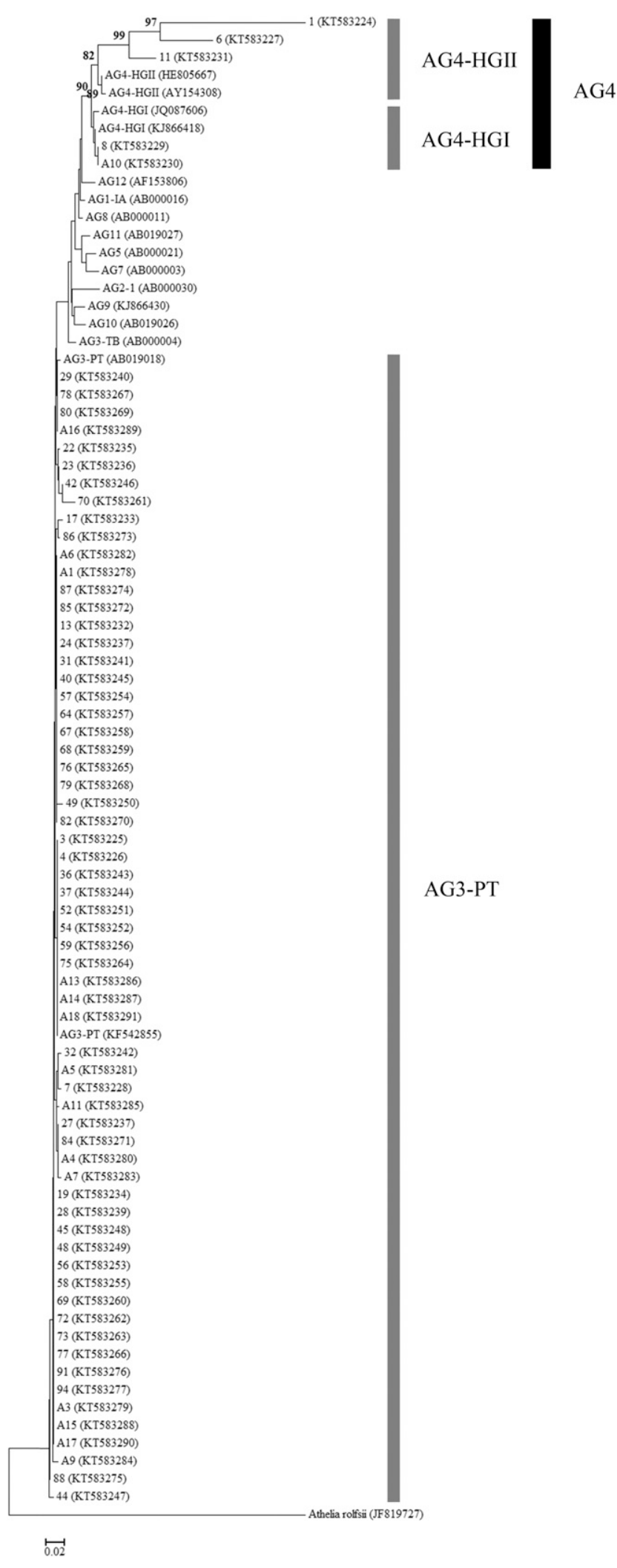

Fig. 1. Phylogenetic tree of Rhizoctonia solani isolates collected from potato tubers with black scurf symptoms was constructed using neighbor-joining analysis, based on the sequences at their internal transcribed spacer (ITS)1-5.8S-ITS2 ribosomal DNA regions. Genetic distances were determined according to Kimura's substitution model (Kimura 1980) and bootstrap support was estimated based on 1,000 trials. Only values over $70 \%$ are shown at the nodes. Scale bar represents one base change per 50 nucleotide positions. Numbers in parentheses are the accession numbers of reference sequences obtained from the National Center for Biotechnology Information. virulence characteristics (Das et al. 2014; Yang et al. 2015), whereas AG5 and all three homogeneous groups (HG) of AG4 (HGI, HGII, and HGIII) have been reported on potato in different parts of the world, mainly causing canker symptoms and, to a lesser extent, black scurf (Balali et al. 1995; Campion et al. 2003; Johnk and Jones 2001; Tsror 2010). Other AG occasionally reported to infect potato are AG1, AG7, AG8, and AG9, with AG8 almost exclusively infecting roots, whereas AG7 infects stems, stolons, and tubers (Carling and Leiner 1990a; Tsror 2010; Woodhall et al. 2008). Rare reports of AG1-1B, AG6, AG10, AG11, AG12, and AG13 have also been mentioned on potato, although many of them lack pathogenicity confirmation (Yanar et al. 2005; Yang et al. 2015). Furthermore, Rhizoctonia spp. other than $R$. solani are thought to have little to no role in causing disease on potato (Carling and Leiner 1990a).

The concomitant presence of multiple AG on infected potato plants in single potato fields (Bains and Bisht 1995), combined with the complexity of the pathogen, makes disease management challenging; thus, integrated approaches should be implemented (El Bakali and Martin 2006). However, sustainability and effectiveness of disease management strategies rely on the understanding of the characteristics and population dynamics of the pathogen. Currently, there is lack of information about the Rhizoctonia population associated with potato black scurf in Cyprus.

Therefore, the scope of this study is to provide information on the genetic composition and biological diversity within the Cyprus black scurf-associated $R$. solani population. More specifically, we examined (i) nuclear condition and AG determination based on hyphal anastomosis, (ii) sequence analysis of the internal transcribed spacer (ITS)1-5.8S-ITS2 rDNA regions, (iii) mycelial growth at different temperatures, (iv) sensitivity to the commonly used fungicide pencycuron, and (v) disease severity (DS) on six crops, including 'Annabelle' potato.

\section{Materials and Methods}

Fungal isolation and characterization. During the period of 2010 to 2011, 42 fields from all major potato-cultivating areas of Cyprus were surveyed, and potato tubers exhibiting pronounced black scurf symptoms were collected. Approximately two tubers with formed sclerotia on their skin were arbitrarily selected per field and two to three sclerotia per tuber were removed and placed on $9-\mathrm{cm}$ petri dishes with potato dextrose agar (PDA) amended with streptomycin sulfate and ampicillin at 100 and $500 \mathrm{mg} /$ liter, respectively. Plates were incubated at $25^{\circ} \mathrm{C}$ and, 2 to 3 days later, cultures were microscopically identified as Rhizoctonia spp. based on their hyphal characteristics (Parmeter and Whitney 1970). Hyphal tips were excised and transferred to new PDA plates at $25^{\circ} \mathrm{C}$ in order to establish pure cultures that were kept at $4^{\circ} \mathrm{C}$ until use. In order to obtain a more weighted representation of the population, an average of two isolates per sampled field were selected, resulting in a total of 96 isolates. Tester isolates of $R$. solani representing AG2-1 (MUCL 51654), AG3 (MUCL 51930) and (CBS 101773), AG4 (CBS 117243), and AG5 (MUCL 51931) were obtained from the Belgian Co-ordinated Collections of Micro-organisms-Mycothèque de l'Université catholique de Louvain (BCCM-MUCL; Louvain-la-Neuve, Belgium) and the Centraalbureau voor Schimmelcultures (CBS; Baarn, The Netherlands) collections. The collected isolates were characterized in terms of nuclear condition and AG according to the "clean-slide" technique, as described by Kronland and Stanghellini (1988). The categories of hyphal anastomosis reactions were scored as follows (Cubeta and Vilgalys 1997): C0, no interaction; C1, hyphal contact; C2, hyphal fusion with killing reaction; and $\mathrm{C} 3$, fusion with no cell death. The fusion and death of anastomose cells were considered an anastomosis-positive reaction. The anastomosis determination procedure with the tester isolates was conducted two times.

DNA extraction and polymerase chain reaction. Liquid cultures of $68 R$. solani isolates were grown in potato dextrose broth for a week at $25^{\circ} \mathrm{C}$. Collected mycelia were lyophilized for $24 \mathrm{~h}$ and DNA was isolated according to Cary et al. (2009). ITS1 and ITS2 regions, including the ribosomal 5.8S RNA gene, were amplified using the universal ITS-1 (5-TCCGTAGGTGAACCTGCGG-3) and ITS-4 
(5-TCCTCCGCTTATTGATATGC-3) primers (Bacharis et al. 2010; Lehtonen et al. 2008). Polymerase chain reaction (PCR) amplification reactions were performed in a $50-\mu l$ reaction containing $5 \mu l$ of $1 \times$ PCR buffer (GeneAmp 10× PCR Buffer II; Applied Biosystems, Foster City, CA), $2 \mu \mathrm{l}$ of dNTP at $200 \mu \mathrm{M}, 0.5 \mu \mathrm{l}$ of each primer at $0.5 \mu \mathrm{M}$ (Microsynth AG, Balgach Switzerland), $0.5 \mu$ l of Taq DNA polymerase at $1 \mathrm{U}$ per $50-\mu l$ reaction (AmpliTaq Gold; Applied Biosystems), $5 \mu \mathrm{l}$ of DNA template at 10 to $50 \mathrm{ng} / \mu \mathrm{l}$, and $36.5 \mu \mathrm{l}$ of sterile distilled water. Amplification was performed using the following program: initial DNA denaturation for $5 \mathrm{~min}$ at $94^{\circ} \mathrm{C} ; 30$ cycles of denaturation for $30 \mathrm{~s}$ at $94^{\circ} \mathrm{C}$, primer annealing for $30 \mathrm{~s}$ at $57^{\circ} \mathrm{C}$, and extension for $1 \mathrm{~min}$ at $72^{\circ} \mathrm{C}$; and a final extension for $5 \mathrm{~min}$ at $72^{\circ} \mathrm{C}$. For purity and sizing purposes, aliquots of the PCR products were loaded on $1.5 \%$ agarose gel in Tris-acetate-EDTA buffer with SYBR Safe DNA gel stain (Invitrogen, Carlsbad, CA).

Sequencing and phylogenetic analysis. Amplicons were purified using isopropanol precipitation in the presence of sodium acetate, collected by centrifugation, and washed with $70 \%$ ethanol. Following a second centrifugation, the wells were briefly dried at $50^{\circ} \mathrm{C}$ prior to resuspension in water. Cycle sequencing at $96^{\circ} \mathrm{C}$ for $1 \mathrm{~min}$, followed by 25 cycles of $96^{\circ} \mathrm{C}$ for $10 \mathrm{~s}, 50^{\circ} \mathrm{C}$ for $5 \mathrm{~s}$, and $60^{\circ} \mathrm{C}$ for $75 \mathrm{~s}$ was performed with either ITS 1 or ITS4 using BigDye chemistry (BigDye Terminators V3.1 kit; Applied Biosystems, Carlsbad, CA). The termination products were subsequently purified, collected, and washed by centrifugation, as previously described. The resultant pellet was resuspended in Hi-Di formamide (Applied Biosystems) and the sample was sequenced. The rDNA-ITS sequence data obtained were compared by BLAST search on the National Center for Biotechnology Information (NCBI) database to determine the AG of individual isolates. Sequences were aligned with Clustal W algorithm integrated into the MEGA 6.0 software package (Tamura et al. 2013) and the phylogenetic relatedness between isolates was calculated using the neighbor-joining (NJ) method (Saitou and Nei 1987) under Kimura's two-parameter model (Kimura 1980) as the substitution model, omitting all sites with gaps. For comparison purposes, rDNA ITS sequences of other isolates of known AG were obtained from GenBank and used in the construction of the NJ tree (Fig. 1).
Bootstrap analysis was performed using 1,000 pseudoreplicates of the data set and only values $>70 \%$ are shown in the phylogenetic tree. The sequence of Athelia rolfsii (GenBank accession number JF819727) was used as outgroup for rooting the phylogenetic tree.

Fungicide sensitivity. In Cyprus, the phenylurea fungicide active ingredient pencycuron (Fungicide Resistance Action Committee Code-20) is recommended for potato seed treatment. The spiral gradient dilution (SGD) method was used for a subset of isolates $(n=68)$ and was conducted as described by Förster et al. (2004). Mycelial inoculum for the SGD plates was grown on hydrophilic cellophane strips (Sigma-Aldrich, St Louis). Cellophane strips ( $n=8$ to 10) were placed on the surface of PDA in 9-cm petri dishes, a 6-mm mycelial plug of $R$. solani was placed in the middle of the plate, and the plates were incubated at $25^{\circ} \mathrm{C}$ for 4 to 5 days. Agar plates $(15 \mathrm{~cm}$ in diameter) were prepared at least $24 \mathrm{~h}$ before the fungicide solution was applied with a spiral plater (Autoplate Spiral Plating System; Advance Instruments Inc., Norwood, MA) using the exponential deposition mode. Plates were incubated for 2 to $4 \mathrm{~h}$ to allow fungicides to diffuse into the medium and form a gradient of concentrations along the radius of the plate. Mycelium-covered strips were placed radially along the gradient at predetermined plate positions. For each fungal isolate, a duplicate sample was placed at the opposite location on the plate, and three replicate plates were prepared for each fungicide. The 2-day incubation option was used in the SGD software (Advance Instruments Inc.) for the calculation of the local concentrations where $50 \%$ growth inhibition was observed ( $\mathrm{EC}_{50}$ values). The molecular weight of pencycuron that was used for the calculations was 329 . All experiments were repeated twice.

Effect of temperature on in vitro growth rate. The radial growth of $79 R$. solani isolates (AG3, $n=74$; AG4-HGI, $n=2$; and AG4HGII, $n=3)$ was measured at three different temperatures $(10,20$, and $\left.30^{\circ} \mathrm{C}\right)$. Mycelial plugs $(6-\mathrm{mm}$ in diameter) were removed from actively growing colonies on PDA, then placed in the center of 9-cm PDA plates and incubated accordingly in the dark in different growth chambers. Colony growth was scored daily by measuring two perpendicular axes until the mycelium reached the edge of the dish, and mean daily growth rate was calculated for each isolate,
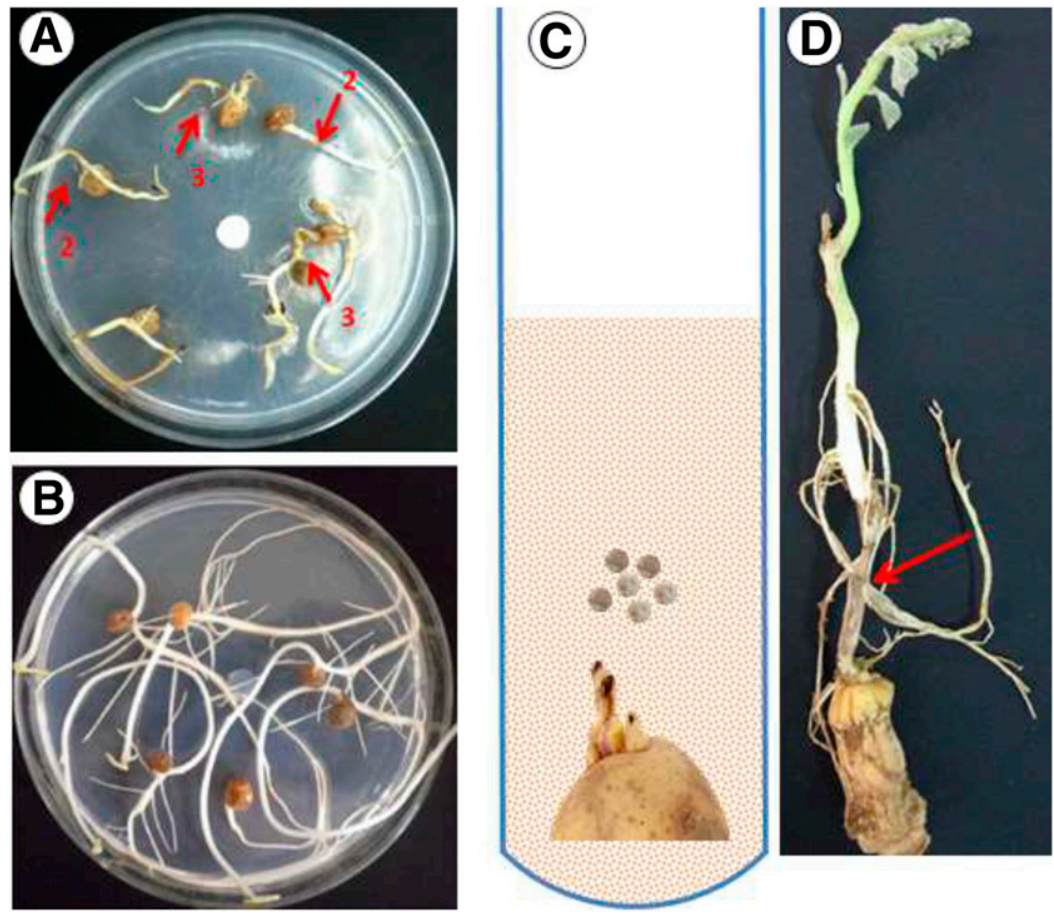

Fig. 2. Disease severity of Rhizoctonia solani isolates was assessed during pathogenicity and aggressiveness assays. For potential rotational crops, a mycelial plug was placed in the center of a petri dish with $2 \%$ water agar that was incubated at $20^{\circ} \mathrm{C}$ in order to let the $R$. solani establish. Surface-sterilized seed were then placed midway to the edge of the plate. A, Plates were incubated and disease severity was assessed 6 days later based on a scale ranging from 0 to 4 . B, Sterile agar plugs were used as controls. C, For potato, a seed piece was placed in a plastic test tube $(40$ by $120 \mathrm{~mm}$ ) on the top of moist sand. Mycelial plugs were placed above the seed, the tube was filled with sand and incubated at $21^{\circ} \mathrm{C}$. D, A month later the inoculated sprouts were observed for symptoms development and disease severity was estimated. Arrowheads point out developed symptoms. 
subtracting the plug diameter from each measurement. Three replicates per isolate were used per temperature and the experiment was performed twice.

Pathogenicity and aggressiveness. Twenty-five isolates were selected to represent all different AG identified in the study. The pathogenicity and aggressiveness of the selected isolates were tested on wheat (Triticum turgidum subsp. durum 'Ekavi'), barley (Hordeum vulgare 'Achna'), vetch (Vicia sativa 'Kimon'), melon (Cucumis melo), and lettuce (Lactuca sativa 'Nader'), using a modification of the method described by Carling et al. (2002). Although crop rotation in Cyprus potato production is not a common practice, the selection of the aforementioned plant species was based on the crops that growers sporadically use. Briefly, $9-\mathrm{cm}$ petri dishes with $2 \%$ water agar were seeded in their center with a 6-mm mycelial plug actively growing on PDA. Sterile agar plugs were used as controls (Fig. 2A and B). The inoculated plates were incubated for 2 days at $20^{\circ} \mathrm{C}$ in order to let the fungal isolates establish; then, 8 seeds per plant species were placed in a circular pattern, halfway between the fungal plug and the edge of the plate. Before their placement in the petri dishes, seeds were surface sterilized in $5 \% \mathrm{NaOCl}$ for 2 min. All treated plates were incubated in a growth chamber in the dark at $20^{\circ} \mathrm{C}$. The germination and development of the seedlings was recorded daily and DS was assessed 6 days after seed were placed on the agar. DS in terms of discoloration, lesions, or death was evaluated using an index ranging from $0=$ no damage to $4=$ dead seedling (Fig. 2A), as described by Carling et al. (2002). Three replications were used per experiment and the experiment was performed twice.

Furthermore, the severity of the same set of isolates was assessed on sprouts of Annabelle potato, employing a method developed by Lehtonen et al. (2008), with slight modifications. More specifically, 20-by-30-mm seed pieces carrying a single emerging sprout were excised by means of a cork borer from certified, pathogen-free potato seed. A week before planting, seed pieces were left in a ventilated and shady spot in order to scab over. Accordingly, each seed piece was placed in a sterile, glass test tube $(25$ by $150 \mathrm{~mm})$ filled with washed sand. Five mycelial agar plugs $(6 \mathrm{~mm}$ in diameter) cut from actively growing colonies on PDA were placed $10 \mathrm{~mm}$ above the seed piece and covered with approximately $40 \mathrm{~mm}$ of sand (Fig. 2C). The tube opening was covered with aluminum foil and tubes were placed in a growth chamber at $21^{\circ} \mathrm{C}$ with a $16-\mathrm{h}$ photoperiod and $70 \%$ relative humidity. Control treatments were inoculated with sterile PDA plugs. A month later, young plants were removed from the tubes and carefully washed to remove debris and DS per sprout was estimated as the proportion of the surface area covered by lesions, according to an index scale where $0=$ no damage, $1=$ minor hypocotyl discoloration, $2=$ discoloration with small necrotic lesions $(<1 \mathrm{~mm}), 3=$ discoloration with large necrotic lesions $(>1 \mathrm{~mm})$, and $4=$ dead seedling. Each sprout was visually evaluated and placed in one of the aforementioned classes (Fig. 2D). The DS value per isolate was calculated by multiplying the number of sprouts in each class by the midpoint of the class and the sum of all values obtained was divided by the total number of sprouts. Five seed pieces were used per fungal isolate and the experiment was performed twice.

In all pathogenicity assays, isolations were made from symptomatic plant tissue onto PDA containing streptomycin sulfate (100 mg/liter) and ampicillin (500 mg/liter). Only $R$. solani cultures were recovered, while no $R$. solani was isolated from the asymptomatic plants.

Statistical analysis. For repeated experiments, the homogeneity of variances was tested using Bartlett's test of homogeneity. Because variances were homogeneous for each experiment, data were combined and further statistically analyzed. Mean $\mathrm{EC}_{50}$ values of the $R$. solani population for pencycuron were plotted in a frequency histogram. $\mathrm{EC}_{50}$ values were $\log _{10}$-transformed and the bin $\left(\mathrm{EC}_{50}\right.$ category) width $h$ for the transformed data were determined using the method of Scott (1979) with the equation $h_{n}=3.49 s n^{-1 / 3}$; where $s$ is an estimate of the standard deviation and $n$ is the number of isolates evaluated. The number of bins was then determined over the range of $\mathrm{EC}_{50}$ values. The $\log _{10}$-transformed $\mathrm{EC}_{50}$ values were tested for normality using the Shapiro-Wilk test. Actual $\mathrm{EC}_{50}$ values were used upon graphical representation for simplicity reasons.
The effect of temperature on hyphal growth and the DS of each AG were analyzed using analysis of variance and least significant difference mean separation procedures. All the statistical analyses were performed using SAS (version 9.4; SAS Institute, Cary, NC).

\section{Results}

Fungal isolation and characterization. In total, 96 sclerotial isolates of Rhizoctonia were collected from the epidermis of potato tubers exhibiting black scurf symptoms out of potato fields in the areas of Ammochostos, Larnaca, and Lefkosia, Cyprus. All isolates were found to be multinucleate after nuclear staining and hyphal anastomosis was performed with all field isolates. AG3 was the dominant group, representing $94.8 \%(n=91)$ of the isolates, while the remaining isolates $(5.2 \% ; n=5)$ anastomosed with the tester isolate CBS 117243, representing AG4.

Sequencing and phylogenetic analysis. Partial amplification of the rDNA ITS1-5.8S-ITS2 region from $68 R$. solani sclerotial isolates yielded an average fragment of approximately $620 \mathrm{bp}$. Sequence data of the PCR products have been deposited in the NCBI database (KT583224 to KT583291) and were used for AG determination. Sixteen reference $R$. solani sequences existing in the same database were included for comparison purposes, while an A. rolfsii sequence (GenBank accession number JF819727) was used for rooting the phylogenetic tree (Fig. 1). In all, 5 isolates were placed in the subgroups AG4-HGI $(n=2,3 \%$; GenBank accession numbers KT583229 and KT583230) and AG4-HGII $(n=3,4.4 \%$; GenBank accession numbers KT583224, KT583227, and KT583231), while the remaining 63 isolates $(92.6 \%)$ belonged to AG3. Sequencing analysis confirmed the AG classification suggested by their hyphal anastomosis characterization. However, only the sequence analysis of the rDNA-ITS region was able to differentiate AG4 subgroups.

Alignment of the obtained sequences revealed the conservation of the 5.8S region of the rDNA gene sequence among all isolates tested, while sequence variability in the ITS 1 and ITS2 regions was apparent (data not shown). The NJ phylogenetic analysis showed that the Cyprus isolates were separated into distinct clusters based on their AG (Fig. 1). All AG3 sequences isolated from potato were grouped together, forming an AG3-PT cluster, and were distinctly separated from an AG3 tobacco-subgroup reference isolate. Similarly, all AG4 isolates formed a separated phylogenetic topology, with two different subclusters for each subgroup (Fig. 1). However, phyllogenetic relatedness within AG4-HGII demonstrated higher genetic variability compared with the AG4-HGI subgroup isolates.

Fungicide sensitivity. The $\log _{10}$-transformed $\mathrm{EC}_{50}$ values for pencycuron were normally distributed within the population as indicated by the Shapiro-Wilk test $(P=0.366)$. $\mathrm{EC}_{50}$ values across all tested isolates for pencycuron ranged from 0.012 to $0.222 \mu \mathrm{g} / \mathrm{ml}$, with mean and median $\mathrm{EC}_{50}$ values of 0.039 and $0.031 \mu \mathrm{g} / \mathrm{ml}$, respectively. The frequency distribution of $\mathrm{EC}_{50}$ as calculated by Scott's formula (Scott 1979) is shown in the histogram of Figure 3. Furthermore, pencycuron sensitivities for each recoded AG and subgroup ranged from 0.013 to $0.099 \mu \mathrm{g} / \mathrm{ml}$ (mean $=0.036 \mu \mathrm{g} / \mathrm{ml}), 0.018$ to $0.024 \mu \mathrm{g} / \mathrm{ml}$ (mean $=$ $0.021 \mu \mathrm{g} / \mathrm{ml}$ ), and 0.067 to $0.222 \mu \mathrm{g} / \mathrm{ml}($ mean $=0.128 \mu \mathrm{g} / \mathrm{ml})$, for AG3, AG4-HGI, and AG4-HGII, respectively. Mean separation statistical analysis indicated that $\mathrm{EC}_{50}$ values for pencycuron were distributed differently among AG and subgroups (Fig. 4), with AG4-HGII sensitivity values being significantly higher compared with the other two groupings of isolates $(P<0.05)$.

Effect of temperature on in vitro growth rate. The optimal hyphal growth of $79 R$. solani black scurf isolates was measured over a temperature range of 10 to $30^{\circ} \mathrm{C}$ (Table 1). The daily radial hyphal growth rate (DRHGR) of single isolates ranged from 1.78 to $14.00 \mathrm{~mm}$ (data not shown). At $10^{\circ} \mathrm{C}$, all isolates exhibited their lowest DRHGR, ranging from 3.44 to $3.81 \mathrm{~mm} /$ day. Optimum growth temperature for the AG3 and AG4 isolates were 20 and $\geq 30^{\circ} \mathrm{C}$, respectively. More specifically, the DRHGR of AG3 isolates was 3.81, 8.18, and $7.05 \mathrm{~mm}$ at 10,20 , and $30^{\circ} \mathrm{C}$, respectively. At $30^{\circ} \mathrm{C}$, AG4-HGI and AG4-HGII exhibited their higher DRHGR, which were 10.73 and $11.79 \mathrm{~mm}$, respectively. However, both AG4 subgroups did not differ significantly in hyphal growth rate across all temperatures tested. 
Pathogenicity and aggressiveness. Although all $R$. solani isolates, across all groupings, caused minimum to severe levels of damage to all rotational hosts evaluated, their aggressiveness was statistically different (Table 2). On average, AG4-HGII isolates were the most aggressive on all hosts. The lowest DS values were recorded for AG3 isolates, whereas the AG4-HGI subgroup was of intermediate aggressiveness, while no damage was observed in the control (uninoculated) seedlings. More specifically, AG3 isolates were highly aggressive on vetch and less damaging on melon seedlings, with DS values of 1.33 and 0.95 , respectively. The highest aggressiveness by the AG4-HGI subgroup was recorded on barley seedlings and the lowest on melon, with DS values of 2.16 and 1.36, respectively. AG4-HGII isolates caused equally high levels of damage on melon and lettuce, with DS values ranging from 3.42 and 3.35, while vetch seedlings were the least affected (Table 2).

The same set of isolates was tested for their pathogenicity on potato sprouts (cultivar Annabelle). The results indicated that $88 \%$

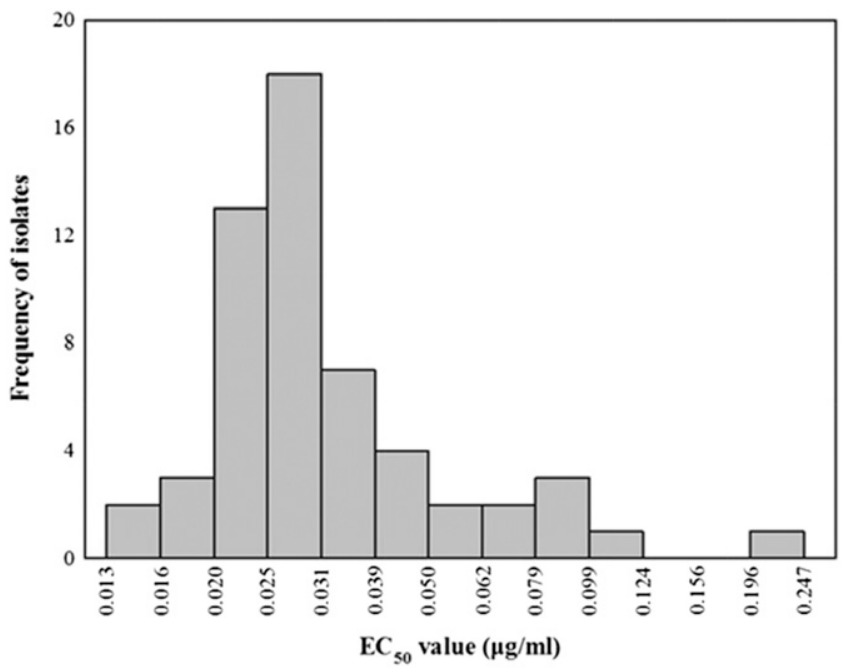

Fig. 3. Frequency histogram of effective concentrations to inhibit mycelial growth of 68 isolates of Rhizoctonia solani by $50 \%$ ( $\mathrm{EC}_{50}$ values) for pencycuron as determined by the spiral gradient dilution method. Bar height indicates the total number of isolates within each bin, and bin width of 0.0996 for pencycuron was based on Scott's method (Scott 1979).

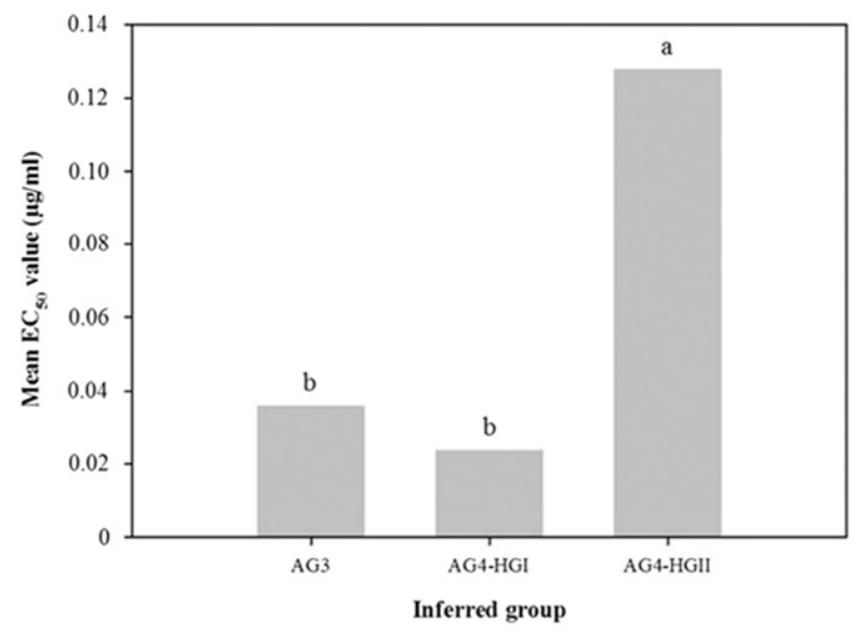

Fig. 4. Distribution of in vitro sensitivities of Rhizoctonia solani anastomosis groups (AG) and subgroups to pencycuron. Concentrations to inhibit mycelial growth by $50 \%$ ( $\mathrm{EC}_{50}$ values) of $R$. solani black scurf isolates $(n=68)$ for pencycuron were determined by the spiral gradient dilution method and mean $\mathrm{EC}_{50}$ values per $R$. solani grouping were calculated. Inferred groups followed by the same letter are not significantly different according to analysis of variance and least significant difference mean separation test $(P<0.05)$. $(n=22)$ of the isolates were capable of causing brown, dry lesions, while the remaining $R$. solani isolates and control sprouts inoculated with sterile agar plugs remained symptom free. The mean DS value, based on the relative size of the damaged area of the sprouts, varied greatly between the tested isolates and ranged from 0 to $88 \%$ (Fig. 5). On the basis of threshold DS values, isolates were classified into three groups of low (>10\%), intermediate (10 to 50\%), and high severity $(>50 \%)$. Twelve $(48 \%)$ isolates were highly aggressive, covering over half of the sprout surface. Six (24\%) isolates caused mild stem canker symptoms, whereas seven $(28 \%)$ isolates fell into the low aggressiveness group, causing minimal to no symptoms (Fig. 5). Differences between the three groups of isolates based on DS values were statistically significant $\left(F_{2,22}=98.5, P<0.0001\right)$. Furthermore, mean DS values were found to be distributed differently among different AG and subgroups (Fig. 5). More specifically, AG4-HGI isolates were highly aggressive (mean DS value $=69.25$ ) on potato sprouts, whereas AG4-HGII isolates were the least aggressive (mean DS value $=3.12$ ). DS values of the AG3 isolates were of intermediate aggressiveness on potato sprouts (Table 3 ).

\section{Discussion}

This is the first comprehensive study taking place in Cyprus that aimed to characterize the AG composition and assess important biological characteristics of the local Rhizoctonia population associated with potato black scurf.

Nuclear composition of isolates indicated that the Cyprus black scurf population was composed solely of $R$. solani, because binucleate Rhizoctonia spp. (BNR) were not isolated. Although most BNR are considered saprophytes (Carling and Leiner 1986), recent studies in China (Yang et al. 2014), Colombia (Ferrucho et al. 2012), Finland (Lehtonen et al. 2008), New Zealand (Farrokhi-Nejad et al. 2007), South Africa (Muzhinji et al. 2015), the United Kingdom (Woodhall et al. 2011), and the United States (Miles et al. 2013) document the implication of BNR with stem canker, black scurf, and other types of blemishes. However, symptoms resulting from BNR isolates were of lower severity compared with AG3 (Lehtonen et al. 2008; Miles et al. 2013; Woodhall et al. 2011; Yang et al. 2014).

Although hyphal anastomosis is generally an accurate and valid method for AG allocation of Rhizoctonia isolates, its resolution at the subgroup level is insufficient. (Fang et al. 2013; Muzhinji et al.

Table 1. Effect of temperature on daily radial hyphal growth rate of Rhizoctonia solani from potato tubers exhibiting black scurf symptoms by anastomosis group (AG) and subgroup on potato dextrose agar

\begin{tabular}{lcccc}
\hline & & \multicolumn{3}{c}{ Hyphal growth rates $(\mathbf{m m})^{\mathbf{y}}$} \\
\cline { 3 - 5 } AG & $\boldsymbol{N}^{\mathbf{z}}$ & $\mathbf{1 0}^{\circ} \mathbf{C}$ & $\mathbf{2 0}^{\circ} \mathbf{C}$ & $\mathbf{3 0}^{\circ} \mathbf{C}$ \\
\hline AG3-PT & 75 & $3.81 \mathrm{a}$ & $8.18 \mathrm{~b}$ & $7.05 \mathrm{~b}$ \\
AG4-HGI & 2 & $3.79 \mathrm{a}$ & $9.54 \mathrm{a}$ & $10.73 \mathrm{a}$ \\
AG4-HGII & 3 & $3.44 \mathrm{a}$ & $9.70 \mathrm{a}$ & $11.79 \mathrm{a}$ \\
\hline
\end{tabular}

y Daily radial hyphal growth rates $(\mathrm{mm})$ per temperature having the same letter are not significantly different according to analysis of variance and least significant difference mean separation test $(P<0.05)$.

${ }^{\mathrm{z}}$ Number of isolates.

Table 2. Disease severity on barley, lettuce, melon, vetch, and wheat seedlings caused by potato black scurf isolates of Rhizoctonia solani belonging to different anastomosis groups (AG) and subgroups ${ }^{\mathrm{y}}$

\begin{tabular}{|c|c|c|c|c|c|c|}
\hline AG & $N^{\mathbf{z}}$ & Barley & Lettuce & Melon & Vetch & Wheat \\
\hline AG3-PT & 20 & $1.21 \mathrm{C}, \mathrm{ab}$ & $1.20 \mathrm{C}, \mathrm{b}$ & $0.95 \mathrm{C}, \mathrm{c}$ & $1.33 \mathrm{C}, \mathrm{a}$ & $1.28 \mathrm{C}, \mathrm{ab}$ \\
\hline AG4-HGI & 2 & $2.16 \mathrm{~B}, \mathrm{a}$ & $1.76 \mathrm{~B}, \mathrm{ab}$ & $1.36 \mathrm{~B}, \mathrm{~b}$ & $1.90 \mathrm{~B}, \mathrm{ab}$ & $2.05 \mathrm{~B}, \mathrm{ab}$ \\
\hline AG4-HGII & 3 & $2.94 \mathrm{~A}, \mathrm{ab}$ & $3.35 \mathrm{~A}, \mathrm{a}$ & $3.42 \mathrm{~A}, \mathrm{a}$ & $2.61 \mathrm{~A}, \mathrm{~b}$ & $3.19 \mathrm{~A}, \mathrm{ab}$ \\
\hline
\end{tabular}


2015; Sharon et al. 2006). However, the sequence variation within the noncoding ITS1 and ITS2 regions of the rDNA supports a more detailed assessment of interspecific genetic diversity (Gonzalez et al. 2001; Kuninaga et al. 1997, 2000; Sharma et al. 2005). Therefore, all collected isolates were characterized by the hyphal fusion method and the acquired information was confirmed on a subset of isolates by sequencing and phylogenetic analysis of their ITS1-5.8S-ITS2 regions. In the Mediterranean, semiarid conditions of Cyprus, AG3 predominated among the sclerotial potato isolates, while AG4 was also recorded in the form of subgroups HGI and HGII, but at low incidence. However, phylogenetic analysis was not adequate to delineate isolates on the basis of their geographic origin. Nevertheless, previous studies document that, although rDNA-ITS analysis supported significant clustering of HGI and HGII subgroups, sequence homology within AG4 ranged from 88 to 97\% (Kuninaga et al. 1997; Sharon et al. 2006), which probably explains why AG4-HGII isolates exhibited a less compact clustering.

The prevalence of AG3 and the overall limited AG variability of $R$. solani populations associated with black scurf has been confirmed in numerous reports worldwide. In France (Campion et al. 2003), New Zealand (Das et al. 2014), Northern Ireland (Chand and Logan 1983), and other countries in the United Kingdom (Woodhall et al. 2007), the concomitant presence of AG3 and AG2-1 was consistent in black scurf, with frequencies ranging from 85.0 to 95.6 and 14.0 to $2.1 \%$, respectively, whereas AG5 was isolated only in New Zealand and Northern Ireland at very low frequencies. It has been documented that AG2-1 survives on tubers as hyphae or in atypical tuber blemishes, where Rhizoctonia is more difficult to isolate (Campion et al. 2003; Woodhall et al. 2008; Yang et al. 2015). Furthermore, the same authors state that AG2-1 produces fewer sclerotia with poor survival on tubers. Thus, a reason for the absence of AG2-1 in the present study might be attributed to the fact that included isolates were collected from tubers with pronounced black scurf symptoms. AG4 has a wide host range (Butler 1993), due to its ability to adapt to variable temperature and cropping pattern regimes (Harikrishnan and Yang 2004). In potato, AG4 is mostly linked to stem canker, although its implication with black scurf has been previously documented (Farrokhi-Nejad et al. 2007). However, AG4-HGI was recently isolated from black scurf in China (Yang et al. 2015) whereas, to

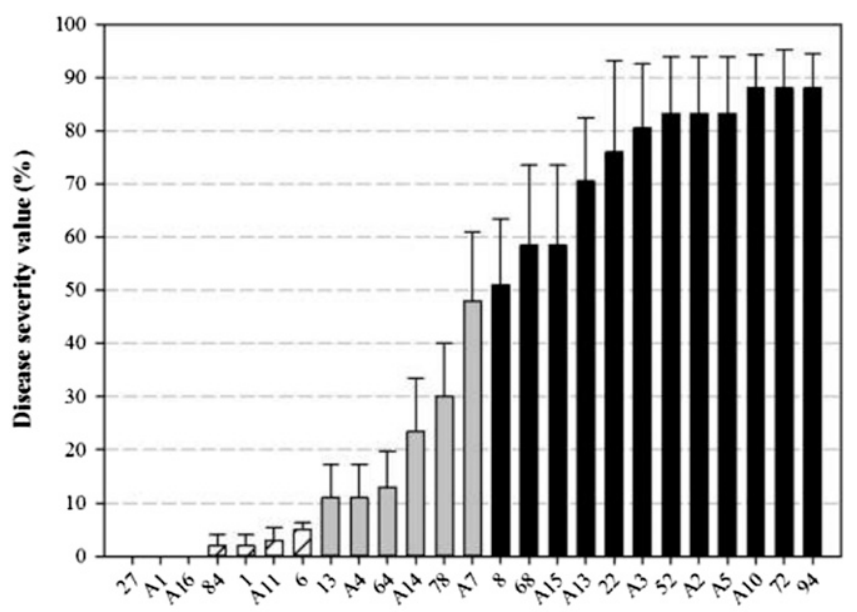

Isolates

Fig. 5. Distribution of disease severity (DS) values caused by black scurf isolates $(n=$ 25) of Rhizoctonia solani was estimated based on the percentage of the potato sprout (cultivar Annabelle) surface covered by lesions according to an index scale ranging from no lesions $(0 \%)$ to more than $75 \%$. Thick bars represent the mean DS value per isolate, while thin bars indicate standard deviation. Based on the DS threshold values of 10 and $50 \%$, the isolates were classified into three aggressiveness groups (low, intermediate, and high), graphically represented by stripped $(<10 \%)$, light-gray $(10$ to $50 \%)$, and dark-gray $(>50 \%)$ columns, respectively. Different groupings were significantly different as evaluated by Fisher's least significant difference test $\left(F_{2,22}=98.5, P<0.0001\right)$. the best of our knowledge, there is no previous report of AG4HGII causing potato black scurf.

Isolates belonging to AG4 subgroups showed faster growth rates than $\mathrm{AG} 3$ at temperatures between 20 and $30^{\circ} \mathrm{C}$. Herein, the higher DRHGR for AG3 isolates was recorded at $20^{\circ} \mathrm{C}$, compared with $\geq 30^{\circ} \mathrm{C}$ for both AG4 subgroups. Similar temperature ranges have previously been reported, underlying the affiliation of AG4 with higher temperatures compared with AG3 (Anguiz and Martin 1989; Bacharis et al. 2010; Banville et al. 1996; Chand and Logan 1983; Ritchie et al. 2009; Sherwood 1969). In their study Carling and Leiner (1990b) documented that isolates of $R$. solani AG3 were also more virulent at cooler temperatures compared with other potato-related AG, including AG4, AG5, and AG8. Because optimum temperatures for mycelial growth are concordant across countries with diverse climatic conditions, it is suggested that $R$. solani isolates do not exhibit temperature adaptation across geographic locations (Bacharis et al. 2010). Furthermore, AG composition of black scurf appears to be unaffected across geographically variable regions, such as the tropical Merida, Venezuela and the subarctic Alaska (Carling and Leiner 1986; Cedeno et al. 2001). Thus, the universally acknowledged domination of Rhizoctonia potato disease by AG3 is most likely attributed to factors other than the temperature requirements of this grouping of isolates.

Garbeva et al. (2006) underlined the decisive importance of aboveground biodiversity to the soil microbial community structure. In support of the aforementioned suggestion, Gudmestad et al. (1989) reported differential AG structure recovered from diseased potato plants sampled from fields with and without previous history of potato. Similarly, Hua et al. (2014) documented the occurrence of different AG to be correlated with different cropping systems and culture practices, suggesting that agricultural practices determine AG associated with Brassica spp. Thus, crop history and cultural practices might be more influential to the population structure of $R h i$ zoctonia. Another important factor that may justify the predominance of AG3 in potato is its greater capacity to produce sclerotia compared with other potato-implicated AG (Balali et al. 1995; Ceresini et al. 2003; Das et al. 2014; Woodhall et al. 2008). In addition to seedborne inoculum, infection can also rise from soilborne infections, although the relative importance of each source is unknown (Tsror (Lahkim) and Peretz-Alon 2005). Thus, potato protection should be integrated and focus on avoiding the introduction of new inoculum through infested seed and the reduction of soilborne inoculum.

Fungicide application, in terms of seed or in-furrow treatments, is considered crucial for successful disease control. However, earlier studies have demonstrated variability of fungicide sensitivities at the inter- and intra-AG level (Csinos and Stephenson 1999; Kataria et al. 1991; Lehtonen et al. 2008; Virgen-Calleros et al. 2000). In Cyprus, chemical control mainly focuses on seed treatment, mostly with the Rhizoctonia selective phenylurea fungicide active ingredient pencycuron. Previous research has demonstrated strong fungicidal activity of pencycuron against certain AG (AG2-2, AG3, AG6, and AG9), whereas other AG have shown moderate to low sensitivity (Tsror 2010; Virgen-Calleros et al. 2000). Mean pencycuron sensitivity $\left(\mathrm{EC}_{50}=0.036 \mu \mathrm{g} / \mathrm{ml}\right)$ among Cyprus AG3 sclerotial isolates was of the same order as reported for AG3 isolates from potato in France

Table 3. Disease severity (DS) on sprouts of potato (cultivar Annabelle) caused by Rhizoctonia solani isolates collected from tubers exhibiting black scurf symptoms belonging to different anastomosis groups (AG) and subgroups.

\begin{tabular}{lccc}
\hline AG & Number of isolates & Mean DS value (\%) & Range (\%) \\
\hline AG3-PT & 21 & $47.15 \mathrm{~b}$ & $0-88$ \\
AG4-HGI & 2 & $69.25 \mathrm{a}$ & $50.5-88$ \\
AG4-HGII & 2 & $3.12 \mathrm{c}$ & $1.65-4.95$ \\
\hline
\end{tabular}

${ }^{\mathrm{z}}$ DS value was defined as the proportion of the sprout surface covered by lesions and was estimated using an index scale ranging from no lesions $(0 \%)$ to more than $75 \%$. Mean DS values followed by different letters are significantly different according to analysis of variance and least significant difference mean separation test $(P<0.05)$. 
$\left(\mathrm{EC}_{50} \leq 0.03 \mu \mathrm{g} / \mathrm{ml}\right)$ and Tunisia $\left(\mathrm{EC}_{50}=0.006 \mu \mathrm{g} / \mathrm{ml}\right)($ Campion et al. 2003; Djébali et al. 2014). Thus, pencycuron seems efficacious against the predominant AG3 R. solani population group related to black scurf in Cyprus. However, the mean $\mathrm{EC}_{50}$ value of subgroup AG4-HGII was significantly higher compared with AG3 and subgroup AG4-HGI. Such differentiation is probably attributed to the ability of certain AG4 isolates to metabolize pencycuron to inactive derivatives (Ueyama et al. 1993). Nevertheless, reduced sensitivity of AG4-HGII isolates could be addressed by the sole or combined application of other fungicides with different modes of action (Campion et al. 2003; Virgen-Calleros et al. 2000).

It has been reported that continuous potato cultivation results in high stem canker incidence levels (approximately $60 \%$ ) by $R$. solani, as compared with 12 to $22 \%$, when rotation crops were included (Peters et al. 2004). Results of pathogenicity studies on potential rotation crops were in accordance with previous reports. Cyprus AG3 isolates were the least virulent among the selected set of hosts. Similar to findings by Eken and Demirci (2003), AG4 isolates were of high to intermediate aggressiveness on vetch. In the same study, they report that AG3 was not pathogenic on vetch whereas, herein, AG3 isolates were of intermediate aggressiveness. Although Kuramae et al. (2003) reported that $R$. solani isolates from melon were more related to AG4-HGI than AG4-HGII, in the present study, both subgroups were found to be pathogenic on the crop. Confirming Van Beneden et al. (2009), AG4-HGI isolates were pathogenic on lettuce; however, AG4-HGII isolates were found to be significantly more damaging. In addition, Demirci (1998) has reported that unlike AG4, AG3 pathogenicity on barley and wheat ranged from very low to moderate; however, pathogenicity data provided by Tewoldemedhin et al. (2006) confirmed the current study, where AG4-HGII isolates were highly aggressive on both crops.

Although AG4-HGII isolates were constantly the most aggressive on all potential rotational crops tested, when pathogenicity was assessed on potato sprouts, the same group of isolates was rated as the least virulent. Despite the fact that AG3 was the predominant aggregate, mean DS was higher for AG4-HGI isolates. However, the severity range for both groups reached the same upper limit, suggesting that individuals within AG3-PT can be highly aggressive. Other researchers have reported AG3-PT isolates to be the most aggressive in causing stem and stolon cankers compared to other AG, while AG4-HGI and AG4-HGII have been found to have moderate to low aggressiveness (Muzhinji et al. 2015; Yang et al. 2015).

In conclusion, this work provides new biological information about the $R$. solani population associated with potato black scurf in Cyprus. It is clear that black scurf is caused predominately by AG3, similar to findings in other potato production areas. However, other AG commonly associated with the disease were not recorded, while isolates belonging to AG4 subgroups HGI and HGII were present. Both rotation crop and cropping sequence are important in shaping the microbial characteristics, soilborne disease, and tuber quality (Larkin and Honeycutt 2006). Thus, despite the beneficial role of crop rotation in managing Rhizoctonia potato disease, the identification of AG4 isolates associated with black scurf, combined with the wide host range of this group, suggests that local growers should be cautious in crop selection.

\section{Acknowledgments}

We thank the extension personnel of the Cyprus Department of Agriculture, Ministry of Agriculture, Rural Development and Environment for their help in sample collection.

\section{Literature Cited}

Anguiz, R., and Martin, C. 1989. Anastomosis groups, pathogenicity, and other characteristics of Rhizoctonia solani isolated from potatoes in Peru. Plant Dis. 73:199-201.

Bacharis, C., Gouziotis, A., Kalogeropoulou, P., Koutita, O., Tzavella-Klonari, K., and Karaoglanidis, G. 2010. Characterization of Rhizoctonia spp. isolates associated with damping-off disease in cotton and tobacco seedlings in Greece. Plant Dis. 94:1314-1322.

Bains, P. S., and Bisht, V. S. 1995. Anastomosis group identity and virulence of Rhizoctonia solani isolates collected from potato plants in Alberta, Canada. Plant Dis. 79:241-242.
Balali, G. R., Neate, S. M., Scott, E. S., Whisson, D. L., and Wicks, T. J. 1995. Anastomosis group and pathogenicity of isolates of Rhizoctonia solani from potato crops in South Australia. Plant Pathol. 44:1050-1057.

Banville, G. J., Carling, D. E., and Otrysko, B. E. 1996. Rhizoctonia disease on potato. Pages 321-330 in: Rhizoctonia Species: Taxonomy, Molecular Biology, Ecology, Pathology and Disease Control. B. Sneh, S. Jabaji-Hare, S. Neate, and G. Dijst, eds. Kluwer Academic Publishers, Dordrecht, The Netherlands.

Bartz, F. E., Cubeta, M. A., Toda, T., Naito, S., and Ivors, K. L. 2010. An in planta method for assessing the role of basidiospores in Rhizoctonia foliar disease of tomato. Plant Dis. 94:515-520.

Butler, R. E. 1993. Rhizoctonia. Pages 87-112 in: Biology of Sclerocial-Forming Fungi. S. D. Lyda and C. M. Kenerley, eds. The Texas Agricultural Experiment Station, The Texas A\&M University System, College Station.

Campion, C., Chatot, C., Perraton, B., and Andrivon, D. 2003. Anastomosis groups and sensitivity to fungicides of Rhizoctonia solani isolates collected on potato crops in France. Eur. J. Plant Pathol. 109:983-992.

Carling, D. E., Kuninaga, S., and Brainard, K. A. 2002. Hyphal anastomosis reactions, rDNA-internal transcribed spacer sequences, and virulence levels among subsets of Rhizoctonia solani anastomosis group-2 (AG-2) and AG-BI. Phytopathology 92:43-50.

Carling, D. E., and Leiner, R. H. 1986. Isolation and characterization of Rhizoctonia solani and binucleate $R$. solani-like fungi from aerial stems and subterranean organs of potato plants. Phytopathology 76:725-729.

Carling, D. E., and Leiner, R. H. 1990a. Virulence of isolates of Rhizoctonia solan AG-3 collected from potato plant organs and soil. Plant Dis. 74:901-903.

Carling, D. E., and Leiner, R. H. 1990b. Effect of temperature on virulence of Rhizoctonia solani and other Rhizoctonia on potato. Phytopathology 80: 930-934.

Carling, D. E., Leiner, R. H., and Westphale, P. C. 1989. Symptoms, signs and yield reduction associated with Rhizoctonia disease of potato induced by tuber borne inoculum of Rhizoctonia solani AG3. Am. Potato J. 66 693-701.

Cary, J. W., Ehrlich, K. C., Beltz, S. B., Harris-Coward, P., and Klich, M. A. 2009 Characterization of the Aspergillus ochraceoroseus aflatoxin/sterigmatocystin biosynthetic gene cluster. Mycologia 101:352-362.

Cedeno, L., Carrero, C., Quintero, K., Araujo, Y., Pino, H., and Rosaima, G. 2001 Identification and virulence of anastomosis groups in Rhizoctonia solani Kühn associated with potato in Merida, Venezuela. Interciencia 26:296-300.

Ceresini, P. C., Shew, H. D., Vilgalys, R., Gale, L. R., and Cubeta, M. A. 2003. Detecting migrants in populations of Rhizoctonia solani anastomosis group 3 from potato in North Carolina using multilocus genotype probabilities. Phytopathology 93:610-615.

Chand, T., and Logan, C. 1983. Cultural and pathogenic variation in potato isolates of Rhizoctonia solani in Northern Ireland. Trans. Br. Mycol. Soc. 81:585-589.

Csinos, A. S., and Stephenson, M. G. 1999. Evaluation of fungicides and tobacco cultivar resistance to Rhizoctonia solani incited target spot, damping off and sore shin. Crop Prot. 18:373-377.

Cubeta, M. A., and Vilgalys, R. J. 1997. Population biology of the Rhizoctonia solani complex. Phytopathology 87:480-484.

Cyprus Statistical Service. 2015. Agricultural statics 2011-2012. Ser. II, Rep. No. 42. Printing Office of the Republic of Cyprus, Nicosia.

Das, S., Shah, F. A., Butler, R. E., Falloon, R. E., Stewart, A., Raikar, S., and Pitman, A. R. 2014. Genetic variability and pathogenicity of Rhizoctonia solani associated with black scurf of potato in New Zealand. Plant Pathol. 63:651-666.

Demirci, E. 1998. Rhizoctonia species and anastomosis groups isolated from barley and wheat in Erzurum, Turkey. Plant Pathol. 47:10-15.

Djébali, N., Elkahoui, S., Taamalli, W., and Hessini, K. 2014. Tunisian Rhizoctonia solani AG3 strains affect potato shoot macronutrients content, infect faba bean plants and show in vitro resistance to azoxystrobin. Australas. Plant Pathol. 43:347-358.

El Bakali, A. M., and Martin, M. P. 2006. Black scurf potato. Mycologist 20: 130-132.

Eken, C., and Demirci, E. 2003. Identification and pathogenicity of Rhizoctonia solani and binucleate Rhizoctonia anastomosis groups isolated from forage legumes in Erzerum, Turkey. Phytoparasitica 31:76-80.

Fang, X., Finnegan, P. M., and Barbetti, M. J. 2013. Wide variation in virulence and genetic diversity of binucleate Rhizoctonia isolates associated with root rot of strawberry in Western Australia. PLoS One 8:e55877.

Farrokhi-Nejad, R., Cromey, M. G., and Moosawi-Jorf, S. A. 2007. Determination of the anastomosis grouping and virulence of Rhizoctonia spp. associated with potato tubers grown in Lincoln, New Zealand. Pak. J. Biol. Sci. 10: 3786-3793.

Ferrucho, R. L., Cifuentes, J. M., Ceresini, P., and García-Domínguez, C. 2012. Rhizoctonia solani AG-3PT is the major pathogen associated with potato stem canker and black scurf in Colombia. Agron. Colomb. 30:204-213.

Fiers, M., Edel-Hermann, V., Héraud, C., Gautheron, N., Chatot, C., Le Hingrat, Y., Bouchek-Mechiche, K., and Steinberg, C. 2011. Genetic diversity of Rhizoctonia solani associated with potato tubers in France. Mycologia 103: 1230-1244.

Förster, H., Kanetis, L., and Adaskaveg, J. E. 2004. Spiral gradient dilution, a rapid method for determining growth responses and $50 \%$ effective concentration values in fungus-fungicide interactions. Phytopathology 94:163-170. 
Garbeva, P., Postma, J., van Veen, J. A., and van Elsas, J. D. 2006. Effect of above-ground plant species on soil microbial community structure and its impact on suppression of Rhizoctonia solani AG3. Environ. Microbiol. 8: 233-246.

Gonzalez, D., Carling, D. E., Kuninaga, S., Vilgalys, R., and Cubeta, M. A. 2001. Ribosomal DNA systematics of Ceratobasidium and Thanatephorus with Rhizoctonia anamorphs. Mycologia 93:1138-1150.

González, D., Cubeta, M. A., and Vilgalys, R. 2009. Phylogenetic utility of indels within ribosomal DNA and $\beta$-tubulin sequences from fungi in the Rhizoctonia solani species complex. Mol. Phylogenet. Evol. 40:459-470.

Gudmestad, N. C., Stack, R. W., and Salas, B. 1989. Colonization of potato by Rhizoctonia solani as affected by crop rotation. Pages 147-252 in: Effects of Crop Rotation on Potato Production in the Temperate Zones. J. Vos, C. D. Van Loon, and G. J. Bollen, eds. Kluwer Academic Publishers, Dordrecht, The Netherlands.

Hane, J. K., Anderson, J. P., Williams, A. H., Sperschneider, J., and Singh, K. B. 2014. Genome sequencing and comparative genomics of the broad host-range pathogen Rhizoctonia solani AG8. PLoS Genet. 10:e1004281.

Harikrishnan, R., and Yang, X. B. 2004. Recovery of anastomosis groups of Rhizoctonia solani from different longitudinal positions and influence of temperatures on their growth and survival. Plant Dis. 88:817-823.

Hua, G. K. H., Bertier, L., Soltaninejad, S., and Höfte, M. 2014. Cropping systems and cultural practices determine the Rhizoctonia anastomosis groups associated with Brassica spp. in Vietnam. PLoS One 9:e111750.

Kataria, H. R., Hugelshofer, U., and Gisi, U. 1991. Sensitivity of Rhizoctonia species to different fungicides. Plant Pathol. 40:203-211.

Kimura, M. A. 1980. A simple method for estimating evolutionary rates of base substitutions through comparative studies of nucleotide sequences. J. Mol. Evol. 16:111-120.

Kronland, W. C., and Stanghellini, M. E. 1988. Clean slide technique for the observation of anastomosis and nuclear condition of Rhizoctonia solani. Phytopathology 78:820-822.

Kuninaga, S., Carling, D. E., Takeuchi, T., and Yokosawa, R. 2000. Comparison of rDNA-ITS Sequences between potato and tobacco strains in Rhizoctonia solani AG-3. J. Gen. Plant Pathol. 66:2-11.

Kuninaga, S., Natsuaki, T., Takeuchi, T., and Yokosawa, R. 1997. Sequence variation of the rDNA ITS regions within and between anastomosis groups in Rhizoctonia solani. Curr. Genet. 32:237-243.

Kuramae, E. E., Buzeto, A. L., Ciampi, M. B., and Souza, N. L. 2003. Identification of Rhizoctonia solani AG 1-IB in lettuce, AG 4 HG-I in tomato and melon, and AG 4 HG-II in broccoli and spinach, in Brazil. Eur. J. Plant Pathol. 109:391-395.

Larkin, R. P., and Honeycutt, C. W. 2006. Effects of different 3-year cropping systems on soil microbial communities and Rhizoctonia diseases of potato. Phytopathology 96:68-79.

Lehtonen, M. J., Ahvenniemi, P., Wilson, P. S., German-Kinnari, M., and Valkonen, J. P. T. 2008. Biological diversity of Rhizoctonia solani AG-3 in a northern potato-cultivation environment in Finland. Plant Pathol. 57:141-151.

McCormack, A. W., Woodhall, J. W., Back, M. A., and Peters, J. C. 2013. Rhizoctonia solani AG3-PT infecting maize stem bases and roots in the United Kingdom. New Dis. Rep. 27:22.

Miles, T. D., Woodhall, J. W., Miles, L. A., and Wharton, P. S. 2013. First report of a binucleate Rhizoctonia (AG-A) from potato stems infecting potatoes and sugarbeet in the Pacific Northwest. Plant Dis. 97:1657.

Misawa, T., and Kuninaga, S. 2010. The first report of tomato foot rot caused by Rhizoctonia solani AG-3 PT and AG-2-Nt and its host range and molecular characterization. J. Gen. Plant Pathol. 76:310-319.

Muzhinji, N., Truter, M., Woodhall, J. W., and van der Waals, J. E. 2015. Anastomosis groups and pathogenicity of Rhizoctonia solani and binucleate Rhizoctonia from potato in South Africa. Plant Dis. 99:1790-1802.

Muzhinji, N., Woodhall, J. W., Truter, M., and van der Waals, J. E. 2014. Elephant hide and growth cracking on potato tubers caused by Rhizoctonia solani AG 3-PT in South Africa. Plant Dis. 98:570.
Parmeter, J. R., Jr., and Whitney, H. S. 1970. Taxonomy and nomenclature of the imperfect state. Pages 7-19 in: Rhizoctonia solani: Biology and Pathology. J. R. Parmeter, ed. University of California Press, Berkeley.

Peters, R. D., Sturz, A. V., Carter, M. R., and Sanderson, J. B. 2004. Influence of crop rotation and conservation tillage practices on the severity of soil-borne potato diseases in temperate humid agriculture. Can. J. Soil Sci. 84:397-402.

Ritchie, F., Bain, R. A., and McQuilken, M. P. 2009. Effects of nutrient status, temperature, and $\mathrm{pH}$ on mycelial growth, sclerotial production and germination of Rhizoctonia solani from potato. J. Plant Pathol. 91:589-596.

Saitou, N., and Nei, M. 1987. The neighbour-joining method: A new method for reconstructing phylogenetic trees. Mol. Biol. Evol. 14:406-425.

Scott, D. W. 1979. On optimal and data-based histograms. Biometrika 66:605-610

Sharma, M., Gupta, S. K., and Sharma, T. R. 2005. Characterization of variability in Rhizoctonia solani by using morphological and molecular markers. Eur. J. Plant Pathol. 153:449-456.

Sharon, M., Kuninaga, S., Hyakumachi, M., and Sneh, B. 2006. The advancing identification and classification of Rhizoctonia spp. using molecular and biotechnological methods compared with the classical anastomosis grouping. Mycoscience 47:299-316.

Sherwood, R. T. 1969. Morphology and physiology in four anastomosis groups of Thanatephorus cucumeris. Phytopathology 59:1924-1929.

Johnk, J. S., and Jones, R. K. 2001. Differentiation of three homogeneous groups of Rhizoctonia solani anastomosis group 4 by analysis of fatty acids. Phytopathology 91:821-830.

Tamura, K., Stecher, G., Peterson, D., Filipski, A., and Kumar, S. 2013. MEGA6: Molecular Evolutionary Genetics Analysis Version 6.0. Mol. Biol. Evol. 30: 2725-2729.

Tewoldemedhin, Y. T., Lamprecht, S. C., McLeod, A., and Mazzola, M. 2006. Characterization of Rhizoctonia spp. recovered from crop plants used in rotational cropping systems in the Western Cape province of South Africa. Plant Dis. 90:1399-1406.

Tsror, L. 2010. Biology, epidemiology, and management of Rhizoctonia solani on potato. J. Phytopathol. 158:649-658.

Tsror (Lahkim), L., and Peretz-Alon, I. 2005. The influence of the inoculum source of Rhizoctonia solani on development of black scurf on potato. J. Phytopathol. 153:240-244.

Ueyama, I., Araki, Y., Kurogochi, S., and Yamaguchi, I. 1993. Metabolism of the phenylurea fungicide, pencycuron, in sensitive and tolerant strains of Rhizoctonia solani. J. Pestic. Sci. 18:109-117.

Van Beneden, S., Pannecoucque, J., Debode, J., De Backer, G., and Höfte, M. 2009. Characterization of fungal pathogens causing basal rot of lettuce in Belgian greenhouses. Eur. J. Plant Pathol. 124:9-19.

Virgen-Calleros, G., Olalde-Portugal, V., and Carling, D. E. 2000. Anastomosis groups of Rhizoctonia solani on potato in central Mexico and potential for biological and chemical control. Am. J. Potato Res. 77:219-224.

Woodhall, J. W., Lees, A. K., Edwards, S. G., and Jenkinson, P. 2007. Characterization of Rhizoctonia solani from potato in Great Britain. Plant Pathol. 56:286-295.

Woodhall, J. W., Lees, A. K., Edwards, S. G., and Jenkinson, P. 2008. Infection of potato by Rhizoctonia solani: effect of anastomosis group. Plant Pathol. 57: 897-905.

Woodhall, J. W., Webb, K. M., Harper, G., Peters, J. C., Rodriguez-Carres, M., and Cubeta, M. A. 2011. First report of a new binucleate Rhizoctonia on potato tubers in the UK. New Dis. Rep. 23:31.

Yanar, Y., Yilmaz, G., Cesmeli, I., and Coskun, S. 2005. Characterization of Rhizoctonia solani isolates from potatoes in Turkey and screening potato cultivars for resistance to AG-3 isolates. Phytoparasitica 33:370-376.

Yang, Y., Zhao, C., Guo, Z., and Wu, X. 2014. Anastomosis group and pathogenicity of binucleate Rhizoctonia isolates associated with stem canker of potato in China. Eur. J. Plant Pathol. 139:535-544.

Yang, Y., Zhao, C., Guo, Z., and Wu, X. 2015. Anastomosis group and pathogenicity of Rhizoctonia solani associated with stem canker and black scurf of potato in China. Eur. J. Plant Pathol. 143:99-111. 